\title{
Siliceous microfossils stratigraphy of the isolation basins at Big Solovetskiy Island (the White Sea, NW Russia) and its implication for paleoreconstructions
}

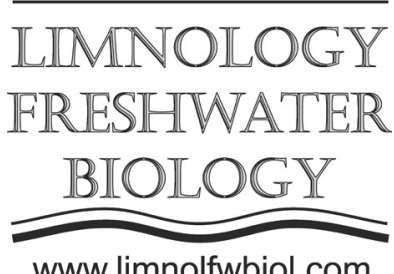

www.limnolfwbiol.com

\author{
Ludikova A.V. ${ }^{1 *}$, Subetto D.A. ${ }^{2}$, Kuznetsov D.D. ${ }^{1}$, Sapelko T.V. ${ }^{1}$ \\ ${ }^{1}$ Institute of Limnology, Russian Academy of Sciences, Sevastyanova str. 9, St. Petersburg 196105, Russia \\ ${ }^{2}$ Herzen State Pedagogical University of Russia, Moika 48, St. Petersburg, 191186, Russia
}

\begin{abstract}
The paper discusses the results of siliceous microfossils studies performed in a "staircase" of four lakes (isolation basins) at Big Solovetskiy Island (Solovki Archipelago). In all the study lakes the siliceous microfossils stratigraphy revealed three main stages of their evolution. The earlier stage, corresponding to being a part of a large basin, is followed by the transitional stage, while the subsequent stage corresponds to a small isolated lake. We argue that besides the traditionally used diatom data, changes in diatom concentrations, floristic diversity, and proportions of chrysophyte cysts and sponge spicules also possess high indicative value, and can be used in paleoenvironmental studies of isolation basins.
\end{abstract}

Keywords: isolation basins, Solovki Archipelago, White Sea, sedimentary records, diatoms, chrysophyte cysts, sponge spicules

\section{Introduction}

The isolation basins approach is widely used in reconstructions of the relative sea-level (RSL) changes. Sedimentary records of the isolation basins (i.e. coastal lakes previously inundated by marine waters, and presently emerged above the sea level) preserve litho- and biostratigraphic signals of the marine transgressions and regressions. Identifying such "signals" is essential for selecting the dating intervals and subsequent building of the RSL curves. The diatoms are the most widely used group of microfossils in RSL studies. Previous studies of the diatom stratigraphy of the isolation basins along the White Sea coasts revealed uneven rates of glacioisostatic uplift often superimposed by neotectonic movements (e.g. Kolka et al., 2015 and references therein).

The current study focuses on the evolution of the coastal basin ecosystems at Big Solovetskiy Island in response to the isolation from the White Sea paleobasins, as recorded in their siliceous microfossils stratigraphy. While using diatoms as a primary group for paleoinferences, we also aim to demonstrate an indicative value of other siliceous microfossils (chrysophyte cysts and sponge spicules) in isolation basin studies.

\section{Materials and methods}

Diatom assemblages were studied in the sediment cores retrieved from Lakes Bol'shoe Zelyonoe $(33 \mathrm{~m}$ a.s.1.), Bol'shoe Korzino (17 m a.s.1.), Svyatoe (8 m a.s.1.) and Isakovskoe (also called Lesnoe Lake, $3 \mathrm{~m}$ a.s.1.) located at Big Solovetskiy Island (Solovki Archipelago, the White Sea). Chrysophyte cysts (siliceous remains of the golden algae) and sponge spicules (structural elements of aquatic invertebrates) were counted alongside with diatoms. Diatom concentrations, floristic diversity index (FDI) "cysts to diatoms" (CY:DI) and "spicules to diatoms" (SP:DI) ratios were subsequently calculated.

\section{Results and discussion}

Extremely low diatom and chrysophyte concentrations at the earliest stage of the evolution of Lake Bol'shoe Zelyonoe indicate unfavourable environments for growth of these microalgae and accumulation. At this stage the lake basin was probably incorporated into the ice lake that gradually occupied the White Sea basin following its deglaciation. The establishing of the small-lake conditions ca. 9200 yr BP (Subetto et al., 2012) is recorded as increased diatom concentrations and species diversity. No signal of marine waters penetration into the Bol'shoe Zelyonoe Lake basin was found in the diatom assemblages dominated by oligotrophic freshwater species. High CY:DI ratios indicate nutrient-poor environments that prevailed in

*Corresponding author.

E-mail address: ellerbeckia@yandex.ru (A.V. Ludikova) 
the lake throughout the Holocene favouring this group of algae.

Diverse marine and brackish-marine benthic taxa prevailed in the diatom assemblages of Lakes Bol'shoe Korzino, Svyatoe and Isakovskoe at the earlier stage of their evolution, indicating shallow-water marinebay environments. Higher FDI values suggest high diversity of benthic habitats in the marine bay and "enrichment" of the diatom assemblages by some deep-water planktonic taxa due to the transportation in highly dynamic littoral environments. Lower diatom concentrations might indicate higher sedimentation rates at this stage and rather unfavorable conditions for diatom accumulation and preservation. Low CY:DI values suggest that chrysophytes do not significantly contribute to the marine microalgal assemblages, while high SP:DI values support the opinion that sponges are more common in marine environments.

The transitional stage related to the decreased marine influence is recorded as rapidly increasing proportion of freshwater epiphytic Fragilariaceae. FDI values accordingly decrease as the diatom assemblages become dominated by 1 or 2 species. Increased diatom concentrations reflect predominantly autochthonous sedimentation in low-energy environments. Higher CY:DI values indicate increased freshwater supply to the isolation basin. The amounts of the spicules derived from marine sponges decreased, while unstable environments of the transitional stage appeared unfavorable for developing the local sponge population, as reflected by decreased SP:DI. This stage started ca 5700 BP in Lake Bol'shoe Korzino, ca 2700 BP in Lake Svyatoe, and ca 2000 BP in Lake Isakovskoe (Subetto et al., 2012).

The start of the lacustrine stage is marked by the predominance of freshwater species. As epiphytic Fragilariaceae remain highly abundant in both Lake Bol'shoe Korzino and Lake Svyatoe, FDI values does not changed much. In Lake Lesnoe where the predominance of freshwater planktonic Aulacoseira spp established soon after the isolation, FDI values are also lower that during the marine stage. Diatom concentrations further increased indicating low-energy lacustrine environments and productive lake ecosystems. As chrysophytes contribution to the microalgal assemblages increased under lacustrine conditions, the CY:DI ratio increased accordingly. The SP:DI ratios remained low reflecting unfavorable environments for these animals to proliferate.

\section{Conclusions}

Studying the siliceous microfossils stratigraphy revealed three main stages of the evolution of the small lakes at Big Solovetskiy Island (the large basin stage, transitional and small lake stages). Each stage is characterized with specific composition of the diatom assemblages, as well different diatom concentrations, floristic diversity, and proportions of chrysophyte cysts and sponge spicules. We therefore argue that all these indicators can be applied to accurately define the isolation contacts, which is essential for the subsequent RSL reconstructions.

\section{Acknowledgements}

The study (methodological part) is partly supported by the RFBR (Grant N 18-55-00008). The work of A. Ludikova contributes to the State Research Program of IL RAS № 0154-2019-0001.

\section{References}

Kolka V.V., Korsakova O.P., Shelekhova T.S. et al. 2015. Reconstruction of the relative level of the White Sea during the Lateglacial - Holocene according to lithological, diatom analyses and radiocarbon dating of small lakes bottom sediments in the area of the Chupa settlement (North Karelia, Russia) Vestnik MGTU 18: 255-268.

Subetto D.A., Shevchenko V.P., Ludikova A.V. et al. 2012. Chronology of isolation of the Solovetskii archipelago lakes and current rates of lake sedimentation Doklady Earth Sciences. 446: 1042-1048. 